\title{
Distribution of pesticide residues in soil due to point source pollution at old Korogwe, Tanzania
}

\author{
Charles KIHAMPA * and Rubhera RAM MATO \\ Ardhi University, Tanzania, P. O. Box 35176, Dar es Salaam, Tanzania \\ * Corresponding author, E-mail: kihampa@yahoo.com, Tel. +255-22-2771272; Fax +255-22-2775448
}

\begin{abstract}
This paper summarizes the findings of a study carried out to assess the levels of pesticide residues in soil along the old obsolete pesticides storage site at Old Korogwe. Gas chromatography spectrophotometry equipped with electron capture detector was used in the identification and quantification of the residues. DDT and its metabolites, DDD and DDE, were detected at different distances from the point source. $p, p$ '-DDT was the predominant residue in all the samples analysed, detected in $92 \%$ of samples at a mean concentration of $425.76 \pm 4.75 \mu \mathrm{g} / \mathrm{g}$. o, $p^{\prime}-\mathrm{DDT}$ was detected in $33 \%$ with a mean concentration of $55.83 \pm 2.65 \mu \mathrm{g} / \mathrm{g}$, metabolites $p, p$ '-DDD and $p, p^{\prime}-\mathrm{DDE}$ were detected in 50\% and 58\% at mean concentrations of $92.5 \pm 3.50$ and $20.84 \pm 1.72 \mu \mathrm{g} / \mathrm{g}$, respectively. The detection of higher level of $p, p^{\prime}-\mathrm{DDT}$ than $o, p^{\prime}-\mathrm{DDT}$ in the samples implies contamination was due to technical-grade DDT.

(c) 2009 International Formulae Group. All rights reserved.
\end{abstract}

Keywords: DDT, DDD and DDE, Obsolete pesticides, Soil Contamination, Old Korogwe.

\section{INTRODUCTION}

Obsolete pesticides refer to pesticide products that have been withdrawn from use for health or environmental reasons. The products have normally deteriorated as a result of improper or prolonged storage. They can neither be used according to its label specification instructions, nor be easily reformulated to become usable again. The deterioration is normally changing chemical and/or physical properties of the pesticides to such an extent that they can no longer be applied with standard or stipulated application equipments (Curtis and Olsen, 2004; Buczyńska and Szadkowska-Stańczyk, 2005; Minh et al., 2006). Obsolete pesticides are a global concern as some belong to persistent organic pollutants (POPs) category, banned from use under the Article 3 of Stockholm Convention (Fernandez and Grimalt, 2003; Adelola, 2004).
It is estimated that $18 \%$ of pesticides in Tanzania is used in the public health sector while $81 \%$ is used in livestock and agricultural sectors, and $1 \%$ is used in other areas including protecting buildings from damage caused by insect pests (Rwazo \& Mkalanga, 2005). In the agricultural sector, insecticides are mostly used for controlling insect pests in cash crops and subsistence crops (A'khabuya and Ledenius, 1988). The increased demand of pesticides in 1970s and 1980s led the Tanzanian Government to import more than 1,264 tons of pesticides most of them organochlorines (NEMC, 2003). Most of the organochlorines and their metabolites have been implicated in a wide range of human health and environmental concerns; as a result their use in agriculture has been banned worldwide for more than 25 years. In Tanzania most of the banned pesticides that were imported in 1970s and 1980s have been accumulated and left 
unattended in improper storage facilities. The accumulation was due to poor import controls, inappropriate purchasing policies, untimely distribution of pesticides, inadequate stock management, aggressive sales practices, pressure to stockpile for unforeseen emergencies, lack of coordination between donor agencies and receipt of outdated or mislabeled products (Curtis and Olsen, 2004).

Before clean up in February 2008, the Old Korogwe site had an over 20 years storage history of about 50 metric tons of persistent pesticides and veterinary waste characterized as DDT (NEMC, 2003). These were deposited within the then Mnyuzi Sisal Estates in 1980s awaiting distribution to users in the Northern Zone of Tanzania. The pesticides were poorly stored, dumped and left in open air without appropriate attention until November 2003 when the store was improved with corrugated iron sheets (NEMC, 2003). However, storage status was still poor, package bags were worn out leaving the bulk of DDT powder vulnerable to wind uptake, which was likely to pose a danger of soil contamination in the area. It is, therefore important to investigate on the levels of these residues in the environment. This may give indications of the extent of contamination and accumulation characteristics of these compounds in various compartments of the environment (Kannan et al., 1995). This work, therefore, seeks to provide baseline information on the levels of pesticide residues and their distribution in soil. The results will be helpful in a scientific assessment of the impact of pesticides on public health, agriculture and the environment in Old Korogwe Town, which may aid in remediation activities.

\section{MATERIALS AND METHODS Sampling}

The old pesticide storage site at Old Korogwe is located within the then Mnyuzi Sisal Estate (latitudes $4^{\circ} 10^{\prime}$ and $4^{\circ} 20^{\prime}$ South of the Equator, longitudes $38^{\circ} 45^{\prime} 38^{\circ} 55^{\prime}$ East of Greenwich) in Korogwe Town, Tanga Region, Tanzania. This was the point source for the purposes of this study. 24 soil samples of $500 \mathrm{~g}$ each were collected from 12 different sampling locations in December, 2007 (Figure
1). Sampling points include $0 \mathrm{~m}$ south, east, west, 30 and $60 \mathrm{~m}$ south, $500 \mathrm{~m}$ north, 30, 60 and $90 \mathrm{~m}$ east and west directions. On the north direction of storage building is a tarmac road and administrative buildings, it was not possible to have a $0 \mathrm{~m}$ sampling point, instead the sample was taken $500 \mathrm{~m}$ away just after the administrative building. The soil samples were collected from $0-30 \mathrm{~cm}$ and $30-60 \mathrm{~cm}$ deep from the top soil. The sampling procedures were conducted as described by Åkerblom (1995).

\section{Chemicals}

All pesticide standards were obtained from the Department of Chemistry, University of Dar Es Salaam, and most of them were of over $99 \%$ certified purity. Concentrations of standard solutions were corrected for the certified purity of standards if below $99 \%$. Individual stock solutions of standard pesticides were prepared by dissolving 10-50 $\mathrm{mg}$ of each compound in cyclohexane and were stored in glass-stoppered flasks at -18 ${ }^{\circ} \mathrm{C}$. Mixed compounds, calibration and measuring standards in cyclohexane were prepared from the stock solutions. Chromatography grade dichloromethane, nhexane, acetone, cyclohexane and ethyl acetate were used. Laboratory glassware were washed with detergents, rinsed with distilled water and acetone, and then dried in an oven at $110{ }^{\circ} \mathrm{C}$ overnight prior to use.

\section{Extraction and clean up}

Two sub-samples of (20 g) each were measured by a weighing balance and subjected under different experimental treatments. One sub-sample was taken in a pre-weighed watch glass for dry weight determination and dried in the oven at $105^{\circ} \mathrm{C}$ to constant weight. Another sub-sample was put in a $(250 \mathrm{ml})$ teflon stoppered flask for pesticides extraction. $14 \mathrm{ml}$ of $0.2 \mathrm{M}$ ammonium chloride solution was added and the mixture swirled for $2 \mathrm{~min}$ and left to stand for $15 \mathrm{~min}$. $100 \mathrm{ml}$ of cyclohexane/acetone mixture $(1: 1 \mathrm{v} / \mathrm{v})$ was added and the flask was tightly stoppered and vigorously shaken for 1 min, and then less vigorously after every 10 $\min$ for $1 \mathrm{~h}$. The contents were then left to stand overnight. Intermittent shaking was 


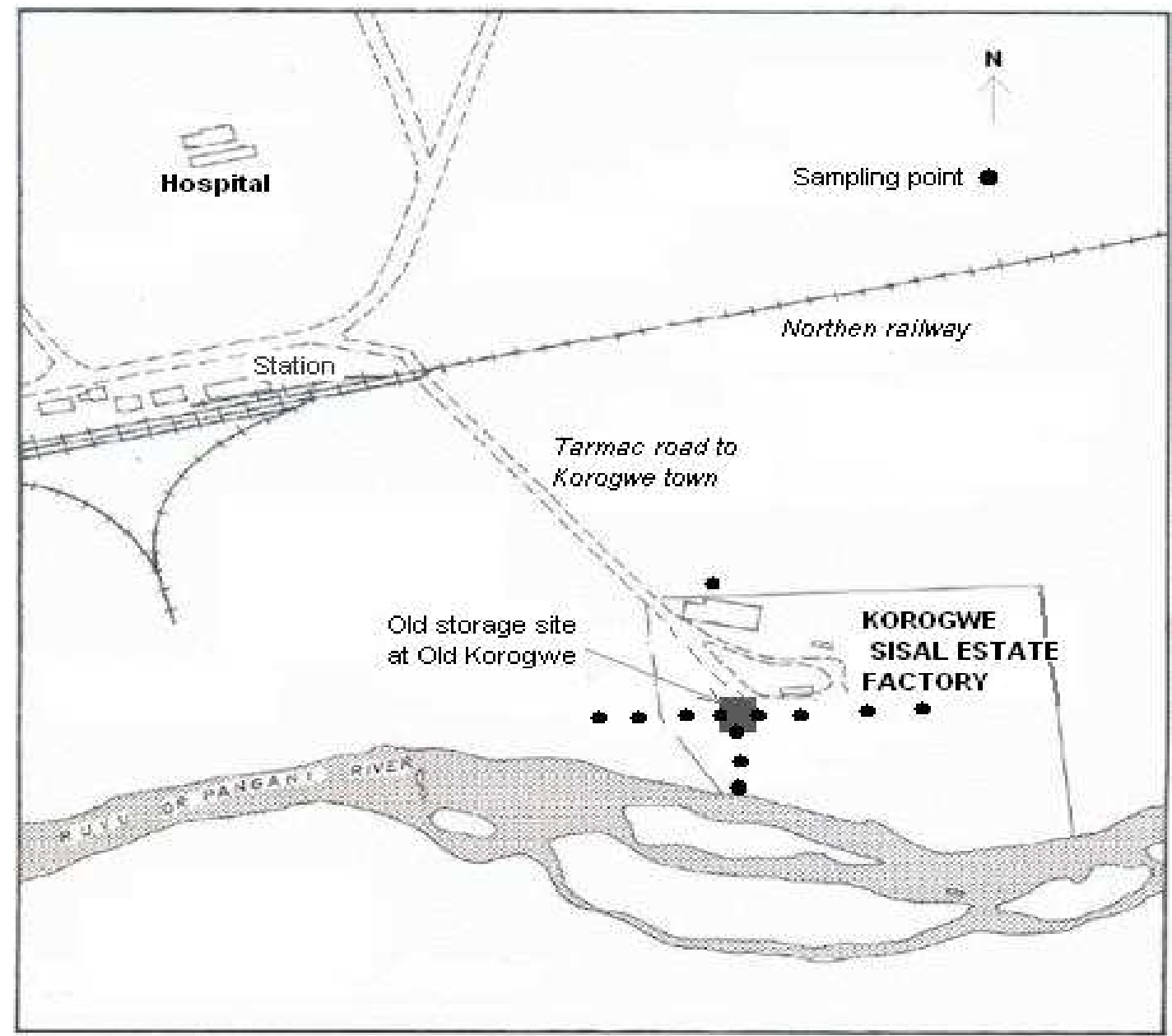

Figure 1: Location of old storage site and sampling points.

continued the next day for two hours and then left to settle. Distilled water was cautiously added to the neck of the flask. The organic phase was pipetted into an E-flask containing anhydrous sodium sulphate (15 g), swirled and left to stand for $15 \mathrm{~min}$. The contents were then decanted through a plug of glass wool into an evaporation flask. The remaining sodium sulphate was rinsed with $20 \mathrm{ml}$ of acetone/cylohexane mixture and decanted through the same glass wool. The resulting extract was concentrated to less than $2 \mathrm{ml}$ of sample extract using a rotary evaporator, solvent changed to cyclohexane/ethylacetate $(1: 1 \mathrm{v} / \mathrm{v}, 1 \mathrm{ml})$ ready for clean up (Åkerblom, 1995).
Gel permeation chromatography (GPC) clean up was performed using $50 \mathrm{~cm} \mathrm{x} 1 \mathrm{~cm}$ i.d. chromatographic tube, with two adaptors, six-way valve with $1 \mathrm{ml}$ sample injector loop and teflon tubing (Pharmacia no SR 10/50), elution with cyclohexane/ethylacetate (1:1 $\mathrm{v} / \mathrm{v})$. The GPC was calibrated using $p, p$ '-DDD and $p, p$ '-DDE (Åkerblom, 1995). Pesticides were eluted in the range $17-36 \mathrm{ml}$. During the clean up, the first fraction $(0-16 \mathrm{ml})$ was discarded. The second fraction (17-36 ml) was collected and concentrated for analyses. The column was cleaned with cyclohexane/ethylacetate $(1: 1 \mathrm{v} / \mathrm{v}, 20 \mathrm{ml})$ before injection of the next sample. The solvent was evaporated and changed to 
cyclohexane/acetone $(9: 1 \mathrm{v} / \mathrm{v})$ to $1 \mathrm{ml}$ of sample extract in vials ready for GC analysis.

\section{Gas chromatographic (GC) analyses}

Analysis of the residues was done as described by Akerblom (1995). Varian Star 3400 gas chromatograph, equipped with SE30 and OV-1701 columns $(30 \mathrm{~m}, 3.2 \mathrm{~mm} \mathrm{x}$ $0.25 \mathrm{~mm}$ film thickness, Hewlett Packard), with a ${ }^{63} \mathrm{Ni}$ electron capture detector was used at the Department of Chemistry, University of Dar es Salaam. Electron capture (EC) and Nitrogen-Phosphorous (NP) detectors were used for analysis. Nitrogen was used as both a carrier and make up gas in the ECD at a flow rate of $30 \pm 1 \mathrm{ml} / \mathrm{min}$. In the NPD, helium was used as a carrier gas at a flow rate of $0.5-1$ $\mathrm{ml} / \mathrm{min}$ and nitrogen at a flow rate of $29 \pm 1$ $\mathrm{ml} / \mathrm{min}$ was used as a make up gas. The temperature programme was $90{ }^{\circ} \mathrm{C}$ held for 1 min, increased at the rate of $30{ }^{\circ} \mathrm{C} / \mathrm{min}$ to 180 $\mathrm{C}$, followed by an increase at the rate of 4 ${ }^{\circ} \mathrm{C} / \mathrm{min}$ to $260{ }^{\circ} \mathrm{C}$ and held for $12 \mathrm{~min}$. The injector and detector temperatures were 250 ${ }^{\circ} \mathrm{C}$ and $300{ }^{\circ} \mathrm{C}$, respectively. Identification of residues was effected by running samples and external reference standards in GC and then comparing the chromatograms (Martens et al., 1999).

\section{Analytical quality assurance}

A $100 \mathrm{ml}$ aliquot of each $\mathrm{n}$-hexane, dichloromethane, cyclohexane, ethyl acetate and acetone was concentrated to $2 \mathrm{ml}$ and used to check the contamination from the reagents used. Two matrix blanks soil were obtained from a virgin land at Ardhi University, Dar Es Salaam. No significant peaks appeared in the chromatograms of the blanks. Recoveries were estimated by spiking the matrix blank with 8 organochlorine pesticide standards at concentrations ranging from 0.01 to $1.1 \mathrm{~g} / \mathrm{ml}$ of each analyte. The average recoveries $\pm \mathrm{SD}(\mathrm{n}=4)$ were as follows: $p, p$ '-DDE $106 \pm 2.3 \%, p, p$ '-DDD $97.7 \pm 0.7 \%, p, p$ '-DDT $81.2 \pm 3.6 \%, o, p^{\prime}-$ DDE $94.5 \pm 1 \%, o, p^{\prime}-D D D 95.7 \pm 0.7 \%$, and o,p'-DDT $81.2 \pm 3.6 \%$. The results were not corrected for recoveries since all were within the normal acceptable range of $70-120 \%$ (Hill, 2000). The detection limits were 0.2 $\mathrm{ng} / \mathrm{g}$ for DDT, DDE and DDD.

\section{RESULTS AND DISCUSSION}

Soil contamination by pesticides have been reported near pesticide dump sites and obsolete pesticide stores in a number of developing countries (Buczyńska and Szadkowska-Stańczyk, 2005; Minh et al., 2006). In our investigation, residues were detected in the samples collected between the top soils to the depth of $30 \mathrm{~cm}$, samples between 30 to $60 \mathrm{~cm}$ depth were below the detection limit. The compounds detected were DDTs ( $p, p^{\prime}$-DDT and $o, p^{\prime}$-DDT) and metabolites $p, p$ '-DDE and $p, p$ '-DDD (Table $1)$. The compounds were widely distributed in the samples of soils investigated, and average distribution concentrations $( \pm \mathrm{SD})$ ranged from 19 to $1650( \pm 4.47) \mu \mathrm{g} / \mathrm{g}$ dry weight (dw) p,p'DDT, below detection limit (bdl) to 260 $( \pm 7.74) \mu \mathrm{g} / \mathrm{g}$ dw $o, p$ '-DDT, bdl to $140( \pm 8.94)$ $\mu \mathrm{g} / \mathrm{g} \mathrm{dw} p, p$ '-DDE and bdl to $300( \pm 14.14)$ $\mu \mathrm{g} / \mathrm{g}$ dw $p, p$ '-DDD. The compounds $p, p^{\prime}-$ DDT was the predominant residue in all the samples analysed, detected in $92 \%$ of samples at a mean concentration of $425.76 \pm 4.75 \mu \mathrm{g} / \mathrm{g}$. $o, p$ '-DDT was detected in $33 \%$ with a mean concentration of $55.83 \pm 2.65 \mu \mathrm{g} / \mathrm{g}$, metabolites $p, p$ '-DDD and $p, p^{\prime}-\mathrm{DDE}$ were detected in $50 \%$ and $58 \%$ at mean concentrations of $92.5 \pm 3.50$ and $20.84 \pm 1.72 \mu \mathrm{g} / \mathrm{g}$, respectively. The highest concentrations were found in samples collected in the vicinity of the point source. These concentrations were decreasing with increasing distance from the point source. A similar observation was obtained from other study (Marco and Kishimba, 2006). The concentrations of $p, p$ '-DDT were greater than those of $o, p$ '-DDT and their metabolites. The mean concentrations of the DDT residues $(\mu \mathrm{g} / \mathrm{g} \mathrm{dw})$ in samples from all sites were in the order $p, p^{\prime}$-DDT (425.76 $\mu \mathrm{g} / \mathrm{g})>p, p^{\prime}-\mathrm{DDD}(92.5 \mu \mathrm{g} / \mathrm{g})>o, p^{\prime}-\mathrm{DDT}$ $(55.83 \mu \mathrm{g} / \mathrm{g})>p$, $p^{\prime}$-DDE $(20.84 \mu \mathrm{g} / \mathrm{g})$. The observed trend is similar to previous data at the point source (Elfvendahl et al., 2004). These concentrations clearly indicate contamination by technical-grade DDT, that primarily consists of $65-80 \% p, p^{\prime}-\mathrm{DDT}$, and 15-21\% o,p'-DDT (Tomlin, 2000). The higher concentrations of $p p^{\prime}$-DDD than $p, p^{\prime}-$ DDT detected in the south direction, can partly be explained by the fact that, 


\section{KIHAMPA and R. RAM MATO / Int. J. Biol. Chem. Sci. 3(3): 422-430, 2009}

Table 1: Concentrations of DDT and metabolites in soil $(\mu \mathrm{g} / \mathrm{g} \mathrm{dw} \pm \mathrm{SD})$.

\begin{tabular}{|c|c|c|c|c|c|c|c|c|c|c|c|c|}
\hline Direction & & South & & & & & & & $\mathbf{E a}$ & & & North \\
\hline $\begin{array}{l}\text { Distance } \\
\text { (m) }\end{array}$ & 0 & 30 & 60 & 0 & 30 & 60 & 90 & 0 & 30 & 60 & 90 & 500 \\
\hline$p, p^{\prime}-\mathrm{DDT}$ & $120 \pm 10.95$ & $80 \pm 6.32$ & $50 \pm 1.41$ & $1600 \pm 6.32$ & $890 \pm 9.48$ & $280 \pm 4.47$ & $19.1 \pm 0.77$ & $1650 \pm 4.47$ & $280 \pm 4.47$ & $110 \pm 6.32$ & $80 \pm 2$ & bdl \\
\hline$o, p^{\prime}-\mathrm{DDT}$ & $140 \pm 6.3$ & bdl & bdl & $260 \pm 7.74$ & $100 \pm 10$ & bdl & bdl & $170 \pm 7.74$ & bdl & bdl & bdl & bdl \\
\hline$p, p^{\prime}-\mathrm{DDE}$ & $40 \pm 2$ & $10 \pm 3.16$ & $0.02 \pm 0.8$ & $30 \pm 1.41$ & bdl & bdl & bdl & $140 \pm 8.94$ & $20 \pm 2$ & bdl & $10 \pm 3.16$ & bdl \\
\hline$p, p '-\mathrm{DDD}$ & $300 \pm 14.14$ & $100 \pm 6.32$ & $60 \pm 6.3$ & $110 \pm 6.32$ & $270 \pm 4.47$ & bdl & bdl & bdl & $270 \pm 4.47$ & bdl & bdl & bdl \\
\hline$\Sigma \mathrm{DDT}$ & 600 & 190 & 110 & 2000 & 1260 & 280 & 19.7 & 1790 & 740 & 110 & 80 & bdl \\
\hline DDE/DDT & 0.33 & 0.13 & 0.01 & 0.02 & 0 & 0 & 0 & 0.08 & 0.03 & 0 & 0.13 & bdl \\
\hline
\end{tabular}


DDD is a degradation product of DDT by anaerobic conversion which is favored by soil microorganism, wetness of the area and sun rays since the area is exposed to the sun almost throughout the day. DDD is also a pesticide of its own which has been sold under the name rothane and has the ISO approved name of TDE (WHO, 1989). These findings indicate that the source of contamination contained DDD as a pesticide, and are consistent with the findings at the point source (Elfvendahl et al., 2004).

The very low DDE/DDT ratios ranging from 0 to 0.33 in all samples (Table 1), indicate inputs of significantly non-degradable DDT from point source (Strandberg and Hites, 2001). Similar results of low DDE/DDT ratios were obtained in soil in the study at the point source, and in leaves of different plant species in relation to a point source (Elfvendahl et al., 2004; Marco and Kishimba, 2006).
The concentrations of total DDT ( $p, p^{\prime}-$ $\left.\mathrm{DDT}+o, p^{\prime}-\mathrm{DDT}+p, p^{\prime}-\mathrm{DDE}+p, p^{\prime}-\mathrm{DDD}\right)$ ranged from $19.7 \mu \mathrm{g} / \mathrm{g}(60 \mathrm{~m} \mathrm{~W})$ to $2000 \mu \mathrm{g} / \mathrm{g}$ $(0 \mathrm{~m} \mathrm{~W}), 80 \mu \mathrm{g} / \mathrm{g}(60 \mathrm{~m} \mathrm{E})$ to $1790 \mu \mathrm{g} / \mathrm{g}(0 \mathrm{~m}$ E), $110 \mu \mathrm{g} / \mathrm{g}(60 \mathrm{~m} \mathrm{~S})$ to $600 \mu \mathrm{g} / \mathrm{g}(0 \mathrm{~m} \mathrm{~S})$. The irregular pattern in the spatial distribution of pesticide residues in west, east and south directions could be attributed to a number of factors including volatilization, winds uptake, rain runoff, children play, and uncontrolled livestock such as goats, sheep and free range chicken that are left to graze around the old storage site. The old storage area is a watershed of the tributaries of Pangani River. The lower DDT concentration on the southern side of the point source can be due to the gradual slopes towards the tributary of the Pangani River, which is about 80 meters from the point source. In this case most of the

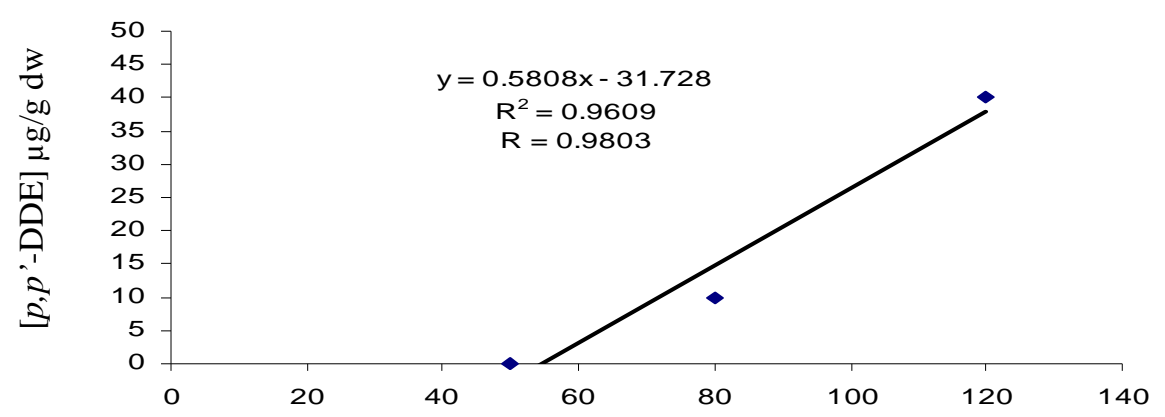

a)

$\left[p, p^{\prime}-\mathrm{DDT}\right] \mu \mathrm{g} / \mathrm{g} \mathrm{dw}$

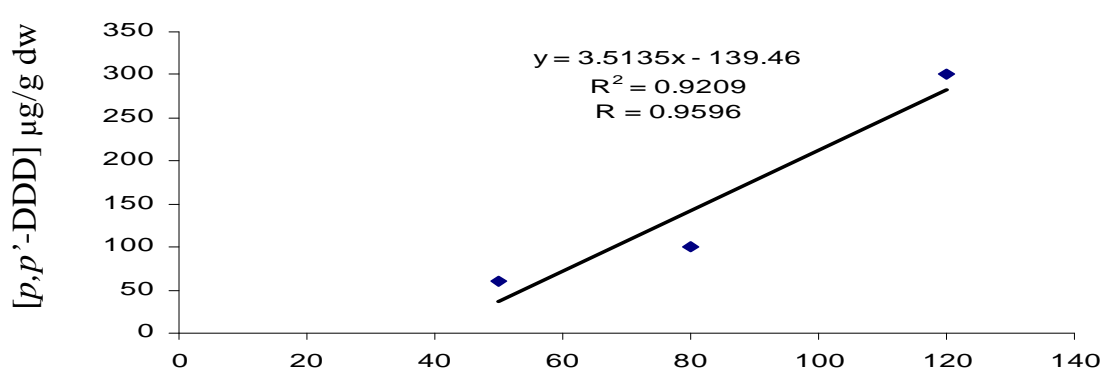

b)

$\left[p, p^{\prime}-\mathrm{DDT}\right] \mu \mathrm{g} / \mathrm{g} \mathrm{dw}$

Figure 2: Correlations in the South direction between concentrations of a) $p, p$ '-DDE and $p, p$ '-DDT $\quad$ b) $p, p^{\prime}$-DDD and $p, p^{\prime}$-DDT. 


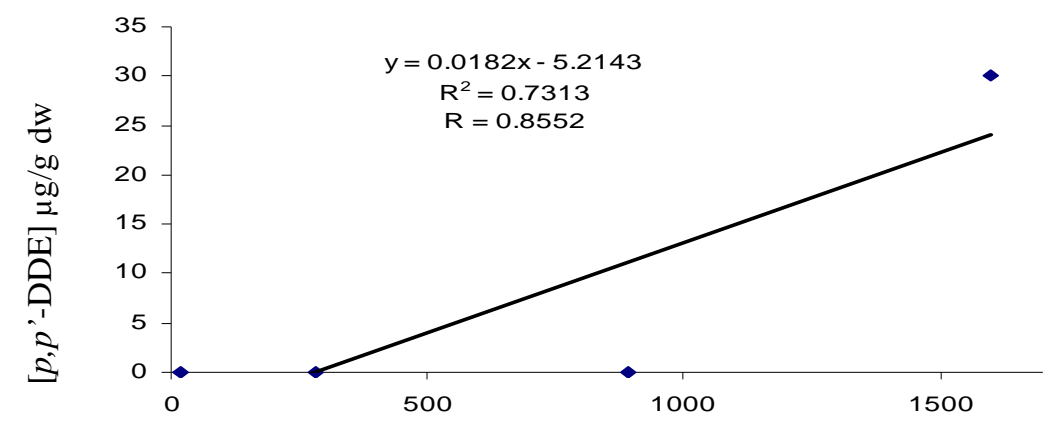

a)

$$
\left[p, p^{\prime}-\mathrm{DDT}\right] \mu \mathrm{g} / \mathrm{g} \mathrm{dw}
$$

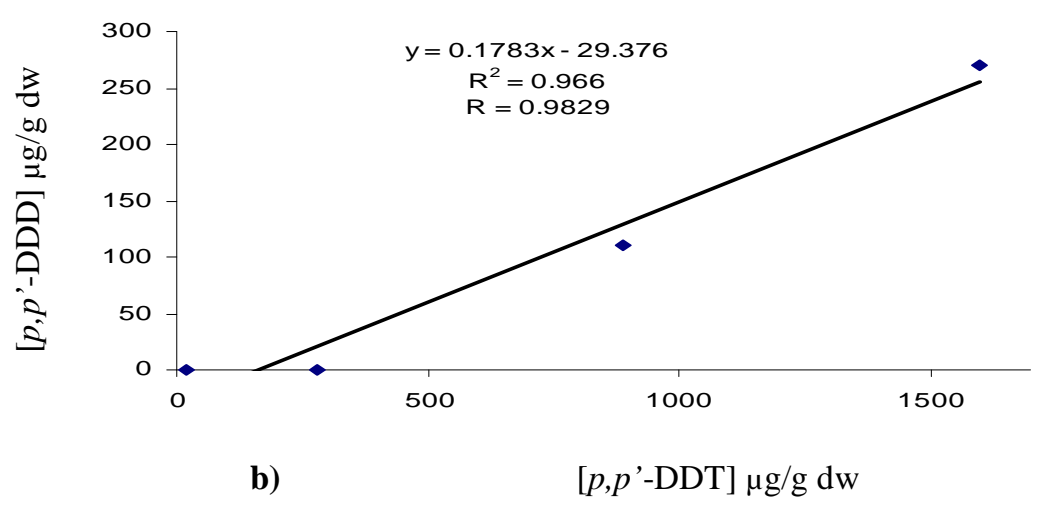

Figure 3: Correlations in the West direction between concentrations of a) $p, p$ '-DDE and $p, p^{\prime}$-DDT $\quad$ b) $p, p^{\prime}$-DDD and $p, p^{\prime}-\mathrm{DDT}$.

top soil containing pesticides has been washed by rain runoff to the river Pangani, thus pose a risk of pesticide contamination to the river and other areas of Pangani River Basin. The east and west directions are relative flat, highest concen-trations of DDTs and metabolites detected near the point source $(0$ and $30 \mathrm{~m})$ could be explained to be due to wind, which blows in the $\mathrm{N}-\mathrm{S}$ direction and occasionally in the SE-NW direction.

There are very strong positive correlations (Figures 2-4) between the concentrations of DDTs and their metabolites. The concentrations of p,p'-DDT and p,p'DDE, p,p'-DDT and p,p'-DDD correlate very strongly $(r=0.85-0.98)$, which suggests that they have a common source.

\section{Conclusion}

The pesticide residues levels obtained from different locations distant from the point source have provided information on the status of soil contamination at Old Korogwe. The results show that residues of organochlorine pesticide are present in soil at various concentrations. In whatever concentration that these residues occurred in the samples, they may further contaminate other environment compartments and may accumulate in vegetable, chickens and milk products and later to higher levels in human beings who consume these products. It is therefore recommended that further research should be conducted into water, grass, sedge and animal products for proper quantification of the magnitude of the pesticide residues contamination. This later information will be useful in establishment of essential mechanisms for monitoring of residues levels in the ecosystem as well as food chain. 


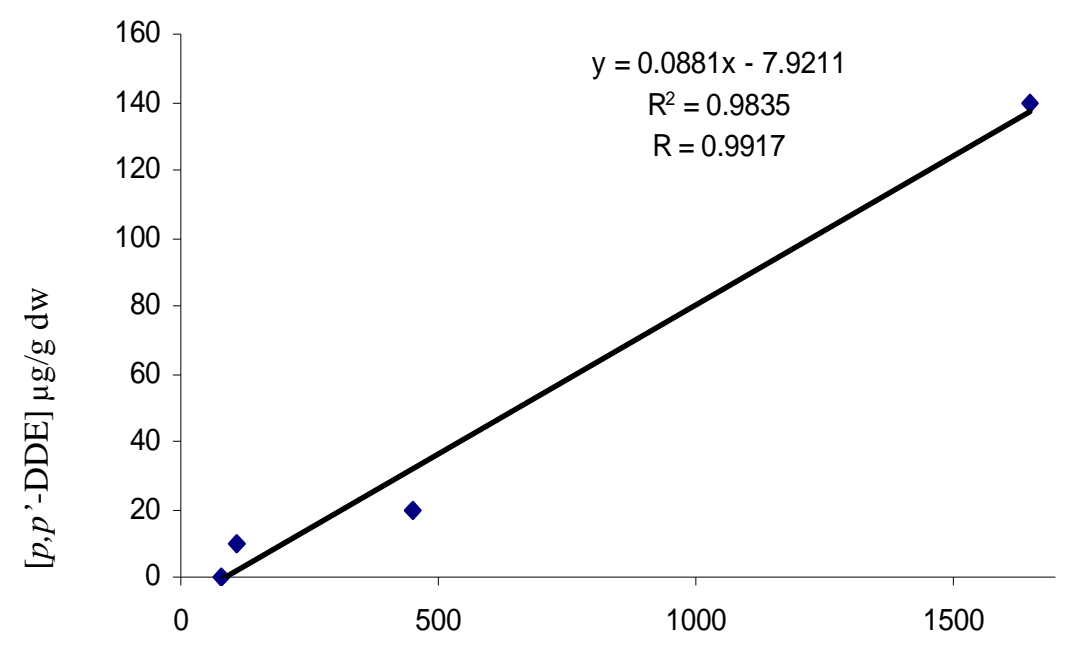

a)

$\left[p, p^{\prime}-\mathrm{DDT}\right] \mu \mathrm{g} / \mathrm{g} \mathrm{dw}$

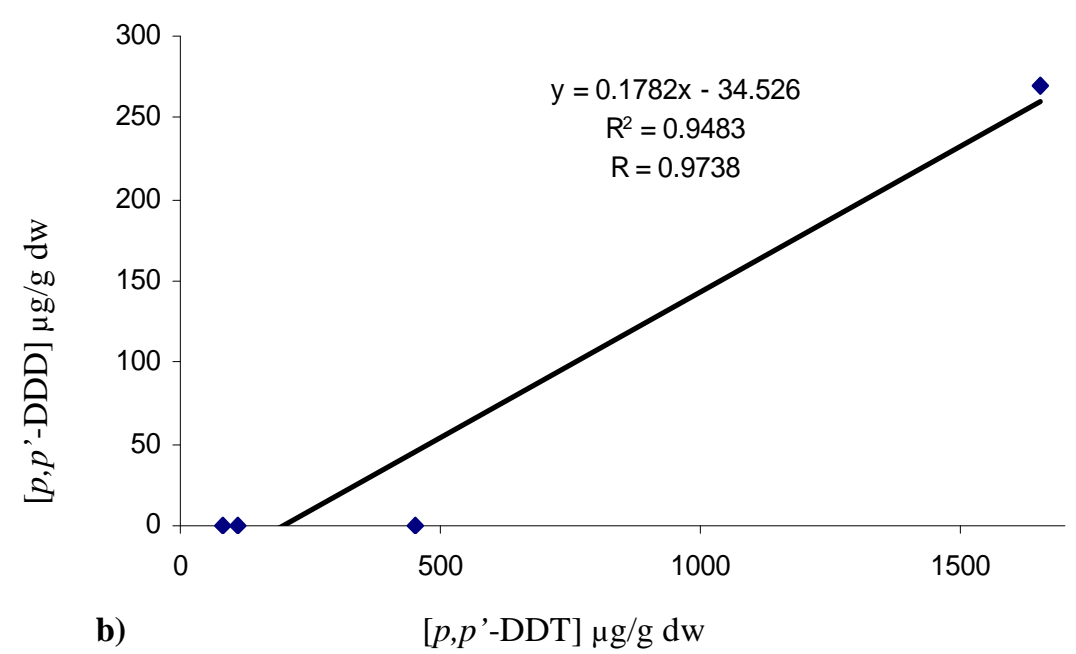

Figure 4: Correlations in the East direction between concentrations of a) $p, p^{\prime}-\mathrm{DDE}$ and $p, p^{\prime}$-DDT, b) $p, p^{\prime}$-DDD and $p, p^{\prime}-\mathrm{DDT}$.

\section{ACKNOWLEDGEMENTS}

We are gratefully acknowledging the inputs of Mr Sechonge Rashid Ally on this work. The management of Korogwe Town Council for financially sponsoring and material assistance in this study. $\mathrm{Mr}$ Mwantobe and Madame Mary (MSc student) of Pesticides Residues Research Group,
Department of Chemistry, University of Dar es Salaam for their invaluable technical assistance during laboratory analysis. The Local Council Management of Korogwe Town Council is also highly acknowledged for the invaluable cooperation paid during field work. 


\section{REFERENCES}

Adelola FB. 2004. The environmental and health impacts of persistent organic pollutants. Hum Ecol. Rev., 11(1): 27-35.

A'khabuya J, Ledenius M. 1988. Pesticides in Tanzania, Department of Environmental Conservation, Universtiy of Helsinki. Publication No 10.

Åkerblom M. 1995. Guidelines for environmental monitoring of pesticide residues for the SADC Region. SADC/ELMS, Monitoring Techniques Series 3, Lesotho.

Buczyńska A, Szadkowska-Stańczyk I. 2005. Identification of health hazards to rural population living near pesticide dump sites in Poland. Int. J. Occup. Med. Environ. Health, 18(4): 331-9.

Curtis C, Olsen CP. 2004. The Africa stockpiles programme: cleaning up obsolete pesticides; contributing to a healthier future. Ind. Environ., 27: 37-8.

Elfvendahl S, Mihale M, Kishimba MA, Kylin H. 2004. Pesticide pollution remains severe after cleanup of stockpile of obsolete pesticides at Vikuge, Tanzania. Ambio., 33(8): 504-509.

Fernandez P, Grimalt J. 2003. On the global distribution of persistent organic pollutants. J. Chimia., 57(9): 514-21.

Hill A. 2000. Quality Control Procedures for Pesticide Residues Guidelines for Residues Monitoring in the European Union $\left(2^{\text {nd }}\right.$ edn). Document no. SANCO/3103/2000, European Commission.

Kannan K, Tanabe S, Tatsukawa R. 1995. Geographic distribution and accumulation features of organochlorine residues in fish in tropical Asia and Oceania. Environ. Sci. Tech., 29: 2673-2683.
Martens D, Schramm KW, Kettrup A. 1999. Standard operation procedures for the determination of chlorinated hydrocarbons in sediments, suspended solids and surface waters. In On the Presence of Polychlorinated Organic Compounds in the Liao River and the Yantse River in Eastern China. European Commission EUR-Report 18702 EN: Ispra; 21-28

Marco JAM, Kishimba MA. 2006. Pesticides and metabolites in cassava, eucalyptus, plum and cashew leaves and roots in relation to a point source in Kibaha, Tanzania. Chemosphere, 64: 542-548.

Minh NH, Minh TB, Kajiwara N, Kunisue T, Subramanian A, Iwata H. 2006. Contamination by persistent organic pollutants in dumping sites of Asian developing countries: implication of emerging pollution sources. Environ. Contam. Toxicol., 50: 474-81.

NEMC (National Environmental Management Council). 2003. African stockpile programme obsolete waste disposal project. Tanzania country report, Dar es Salaam.

Rwazo A, Mkalanga H. 2005. Tanzania tackles unlawful pesticide sales. Pesticide. PAN UK, News Letter.

Strandberg B, Hites RA. 2001. Concentration of organochlorine pesticides in wine corks. Chemosphere, 44: 729-735.

Tomlin C. 2000. The Pesticide Manual $\left(12^{\text {th }}\right.$ edn). Crop Protection Publications: London.

WHO. 1989. DDT and its derivativesenvironmental aspects: environmental health criteria 83. International Programme on Chemical Safety (IPCS). 